NOTE

\title{
Habitat complexity mitigates trophic transfer on oyster reefs
}

\author{
Jonathan H. Grabowski ${ }^{1,4}$, Sean P. Powers ${ }^{2,3}$ \\ ${ }^{1}$ University of North Carolina at Chapel Hill, Institute of Marine Sciences, Morehead City, North Carolina 28557, USA \\ ${ }^{2}$ Department of Marine Sciences, University of South Alabama, Mobile, Alabama 36688, USA \\ ${ }^{3}$ Dauphin Island Sea Lab, Dauphin Island, Alabama 36528, USA \\ ${ }^{4}$ Present address: Gulf of Maine Research Institute, PO Box 7549, Portland, Maine 04573, USA
}

\begin{abstract}
Structured habitats within several aquatic systems have been characterized as having higher abundances of both predators and their prey. Understanding this somewhat paradoxical phenomenon requires teasing apart how habitat complexity influences predator-prey dynamics. To determine whether habitat complexity influences predator foraging efficiency, we measured predator foraging rates within structurally simple and complex habitats. We selected as our test system mud crabs feeding on juvenile hard clams within biogenic reefs formed by the eastern oyster. At low and intermediate crab densities, foraging rates of mud crabs were similar between simple and complex habitats. However, at high crab densities foraging rates were higher for crabs in the complex reefs than in the simple reefs. In addition to providing refuge to both intermediate predators and their prey, habitat complexity appears to enhance predator foraging efficiency by reducing interference competition among predators. In systems where interference competition among densely populated predators may be intense, complex habitats may not provide survival benefits to all trophic levels.
\end{abstract}

KEY WORDS: Mercenaria mercenaria $\cdot$ Panopeus herbstii $\cdot$ Habitat complexity · Interference competition $\cdot$ Density dependence $\cdot$ Oyster reefs

\section{INTRODUCTION}

Biogenic habitats such as seagrass beds, oyster reefs, and coral reefs create structurally complex habitats that generally have higher densities of macroinvertebrate prey than unstructured mud bottom habitats (Summerson \& Peterson 1984, Lenihan \& Peterson 1998). Within a particular habitat of varying complexity (e.g. sea grass patches with different grass blade densities), macroinvertebrate densities and species richness generally are positively correlated with structural complexity (Crowder \& Cooper 1982, Diehl 1988, Diehl 1992, but see Fonseca et al. 1996, Kelaher 2003). Experimental studies have demonstrated that enhanced habitat structure increases prey survival (Heck
\& Thoman 1981, Crowder \& Cooper 1982, Schriver et al. 1995, Beukers \& Jones 1997, Grabowski 2004), and that the spatial extent of prey is often constrained by the availability of refuge (Beck 1997, Gutierrez et al. 2003). Irrespective of reducing predatory controls, biogenic habitats that create emergent structure may enhance densities of prey by baffling water and subsequently enhancing the deposition of food and settlement of larvae or post-larvae (Tegner \& Dayton 1981, Summerson \& Peterson 1984, Commito \& Rusignuolo 2000, Reise 2002).

In addition to small-invertebrate prey, intermediate predators such as juvenile fish and transient macroinvertebrates also aggregate within complex habitats (Summerson \& Peterson 1984, Lenihan et al. 2001, Hei- 
thaus \& Dill 2002). Although foraging in structurally complex habitats may be more difficult than unstructured habitats for intermediate predators (Summerson \& Peterson 1984), added structural complexity reduces the foraging success of higher-order consumers and thus may increase survivorship of intermediate predators (Diehl 1992, Schriver et al. 1995, Corona et al. 2000, Grabowski 2004). Intermediate predator use of suboptimal foraging habitats that offer refuge suggests that predation risk from higher-order consumers is intense (Sih 1980, Werner et al. 1983, Werner \& Hall 1988). Several investigations have determined that top predators induce many intermediate predators such as juvenile American lobsters Homarus americanus and other crustaceans to seek shelter and forage less in open habitat (Wahle 1992, Appleberg et al. 1993, Spanier et al. 1998). Yet other studies have found that foraging efficiency of top predators is maximized within intermediate or even higher levels of structural complexity, presumably as a result of increased prey densities or decreased predator detection within more complex habitats (Crowder \& Cooper 1982, Winfield 1986).

Independent of prey density, habitat complexity may also impact predator foraging efficiency by influencing behavioral interactions among predators and their prey (Werner \& Peacor 2003, Schmitz et al. 2004). In systems where competitive interactions among predators are strong, habitat complexity could alter predator foraging efficiency by decreasing encounter rates of predators and thus reducing interference behavior. Clark et al. (1999) documented that interference behavior among blue crabs Callinectes sapidus reduced their foraging efficiency, and that more widely distributed prey patches decreased interference interactions by reducing intraspecific encounter rates among crabs. Increased structural complexity also may decrease encounter rates and thus increase foraging efficiency. Experiments that address how habitat complexity impacts intra- and interspecific competitive interactions among predators and the consequences for prey survivorship are limited. In this study, we identify whether habitat complexity affects mud crab Panopeus herbstii predation on juvenile hard clams Mercenaria mercenaria at multiple predator densities to assess if habitat complexity influences intraspecific interactions among mud crabs. Specifically, we manipulated mud crab density and structural complexity of oyster reef habitats within mesocosms to determine how these factors influence crab foraging rates.

\section{MATERIALS AND METHODS}

We conducted experiments in a concrete settling tank $(6 \times 9 \times 1.2 \mathrm{~m})$ at the University of North Carolina
Institute of Marine Sciences (UNC-IMS) laboratory in Morehead City, North Carolina, in May 2002. Unfiltered seawater from Bogue Sound, North Carolina, was pumped $\left(0.27\right.$ to $\left.0.29 \mathrm{l} \mathrm{s}^{-1}\right)$ into the concrete tank continuously during the experiment, maintaining a constant depth of $1.2 \mathrm{~m}$. To test the effects of predator density and habitat complexity, we submerged individual square $(0.6 \times 0.6 \times 1.0 \mathrm{~m})$ mesocosms evenly spaced within the settling tank. Mesocosms consisted of a wooden tray $(0.6 \times 0.6 \times 0.2 \mathrm{~m})$ as the base and $6.25 \mathrm{~mm}$ mesh plastic fencing along the sides and top. Each mesocosm was elevated on cinder blocks $0.5 \mathrm{~m}$ above the bottom of the settling tank so that mesocosms extended just above the water surface. Tops were removable to permit construction and breakdown of experimental reefs.

We tested whether habitat complexity affects foraging rates of mud crabs on hard clams at 3 densities $\left(11,22\right.$, and $\left.44 \mathrm{~m}^{2}\right)$ of mud crabs. These 3 densities represent a realistic range of mud crabs on oyster reefs in the wild (Meyer et al. 1996, Grabowski 2002). Reef construction consisted of a sand (20 l) base in each mesocosm followed by unaggregated oyster shell (20 1) in each of 6 mesocosms (simple reefs), or oyster clusters $(20$ l) on top of unaggregated shell $(20 \mathrm{l})$ in each of the other 6 mesocosms (complex reefs). Oyster clusters extended 10 to $30 \mathrm{~cm}$ upward from the unaggregated shell, and created an irregular, high vertical relief in contrast to simple reefs ( $<5 \mathrm{~cm}$ vertical relief). One hundred juvenile clams (mean 13.7 \pm 0.1 SE mm shell length) were deposited after adding sand to each experimental mesocosm, and were buried before adding shell material. Clams were obtained from D. Gilgo's aquaculture lease in the Newport River, Carteret County, North Carolina, and were stored in upwellers at UNC-IMS prior to use in the experiment. Each of 2 high and 2 low complexity reefs received 4,8 , and 16 mud crabs $(32.8 \pm$ $0.7 \mathrm{~mm}$ carapace width) after mesocosms were submerged in seawater. Previous experiments of crab consumption on oysters and clams within this experimental arena determined that bivalve survivorship is $>98 \%$ in the absence of crab predators (Grabowski 2004, unpubl. data). Mud crabs were collected on oyster reefs in Back Sound, Carteret County, North Carolina, and held in upwellers at UNC-IMS prior to use in the experiment.

Living, dead, and missing mud crabs and clams were quantified after $48 \mathrm{~h}$ to avoid prey depletion (maximum prey depletion of $59.9 \pm 4.2 \%$ occurred in the high crab density-complex habitat treatment). A very small proportion $(2.4 \%)$ of mud crabs was missing or dead at the end of each experimental run. Broken remnants of clam shells were retrieved in all pools and suggested predation by crabs. Because pre- 
Low Crab Density

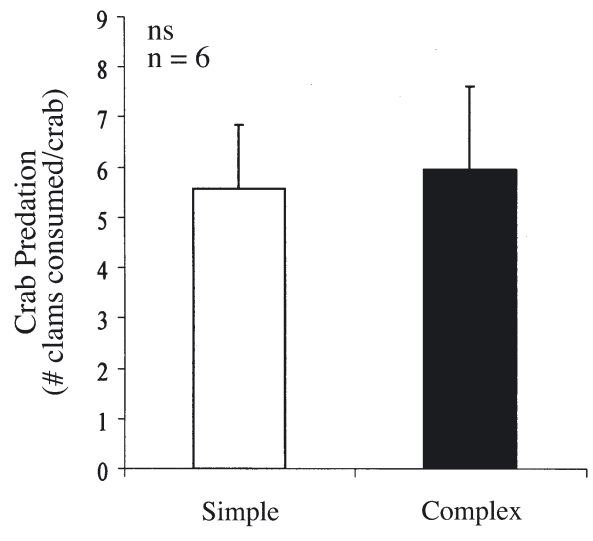

Medium Crab Density

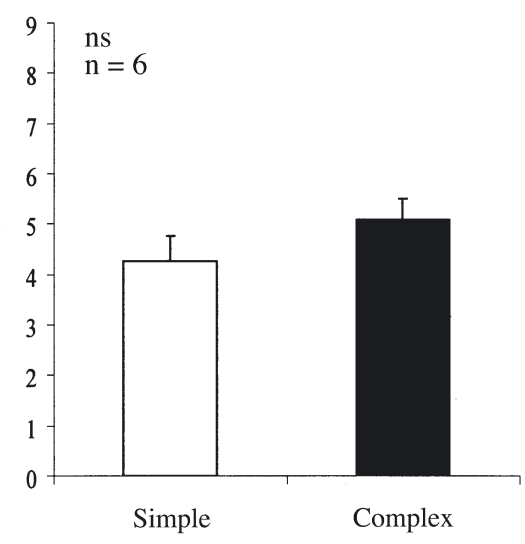

Habitat Complexity

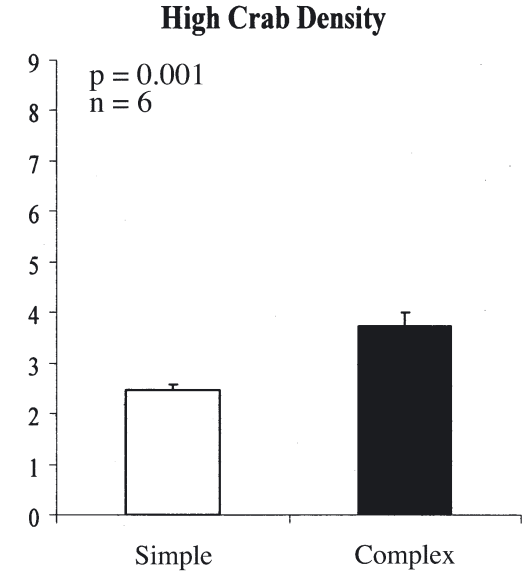

Fig. 1. Foraging rates (mean $+1 \mathrm{SE}$ ) of mud crabs on hard clams in structurally simple versus structurally complex oyster habitat at 3 different densities of mud crabs. Results of unpaired $t$-test are given in the upper left-hand corner of each panel. ns: not significant

liminary trials in the absence of predators indicated that clam survival and retrieval was extremely high $(>98 \%$ ) in our mesocosms, we assumed that missing clams were dead and consumed by mud crabs. Space limitations within the tank permitted only 2 replicates of each treatment in any given experimental trial; therefore, we conducted three $48 \mathrm{~h}$ trials and treated each experimental trial as a block to achieve a total of 6 replicates of each treatment. After each experimental trial was completed, we removed and sieved all shell and sand material from the pools and quantified mortality levels. Before beginning a new experimental run, we randomly reassigned treatments and reconstructed reefs within mesocosms. Before each experimental run, we collected additional mud crabs to avoid reusing crabs that may have been conditioned during previous experimental runs. Additional small prey organisms such as isopods, amphipods, polychaetes, and mollusks entered the individual enclosures via the UNC-IMS water pumping system (Martin et al. 1989, Grabowski 2004). For each enclosure, we analyzed individual crab predation on clams to standardize for patterns in clam mortality attributable to differences in crab density. Specifically, crab predation was calculated after each experimental run for each mesocosm by dividing clam mortality by the average number of crabs in each mesocosm during the course of the experimental run. Finally, we tested if habitat complexity affects foraging rates of mud crabs at each density using separate, unpaired $t$-tests. Violation of the assumption of homogeneity of the variances precluded the use of a 2-way ANOVA to examine the interaction between habitat complexity and crab density on crab foraging rates.

\section{RESULTS AND DISCUSSION}

The effect of habitat complexity on foraging rates of mud crabs was dependent upon crab density. At low crab density (4 crabs per mesocosm), habitat complexity did not affect foraging rates of mud crabs $\left(t_{10}=0.2\right.$; $\mathrm{p}=0.86$; Fig. 1). Crab foraging rates ranged from 5.6 clams per crab per experimental run on simple reefs to 6.0 clams per crab on more complex reefs. Habitat complexity also did not affect foraging rates of mud crabs at the medium density (8 crabs per mesocosm). Crab foraging rates were slightly lower on simple reefs (4.3 clams per crab per experimental run) than on more complex reefs (5.1 clams per crab per experimental run), though this trend was not significant $\left(t_{10}=1.3\right.$; $\mathrm{p}=0.22$ ). Crabs consumed $51.5 \%$ more clams on complex reefs ( 3.7 clams per crab per experimental run) than on simple reefs (2.5 clams per crab per experimental run) when crab density was high (16 crabs per experimental mesocosm; $\left.t_{10}=4.4 ; \mathrm{p}=0.001\right)$. We did notice a trend regardless of habitat complexity that variances were greatest at the low density, moderate at the intermediate density, and lowest at the high density, suggesting that experimental power may have been insignificant to detect differences at the lower crab densities. However, crabs at the lowest density consumed only $6.7 \%$ more clams on complex than on simple reefs, indicating that the effect of habitat complexity on intraspecific interactions among crabs and their foraging rates at lower crab densities is largely diminished, if not completely insignificant.

Added reef complexity may not affect mud crab foraging at low or intermediate crab densities, but it enhanced mud crab foraging rates on juvenile clams at 
high crab densities. This finding is counter to a previous study by Grabowski (2004), in which habitat complexity reduced mud crab foraging efficiency on juvenile oysters Crassostrea virginica, an epifaunal prey common within oyster reefs. Because juvenile oysters are located within the shell matrix, added complexity probably reduces crab-oyster encounter rates, resulting in reduced crab foraging rates on oysters. On the other hand, added complexity apparently does not reduce crab-clam encounter rates, perhaps because juvenile hard clams are located slightly beneath the shell matrix. Mud crab densities were stocked at a density of $\sim 20$ crabs m$^{-2}$ in Grabowski (2004), which is similar to our intermediate density and below the threshold at which interference interactions were modified by habitat complexity in our clam study.

Although decreases in individual feeding rate were evident as crab density increased in our study, this decrease was significantly greater in the high crab density-simple habitat treatment than the high crab density-complex habitat treatment. Because prey density was constant across our experiment, a factor other than prey density was controlling foraging rates. The most plausible explanation for the observed pattern of higher crab foraging success in complex than in simple habitats at high crab density is that higher structural complexity reduces interference among crabs. Aggressive behavior within crab populations is well established (Beck 1997, Clark et al. 1999). Thus, increasing structural complexity would minimize contact among crabs and as a consequence reduce intraspecific interactions.

Complex habitats often are characterized by dense assemblages of predators and prey in part because habitat complexity typically increases prey survival. For instance, intertidal oyster reefs with greater habitat complexity have almost an order of magnitude greater bivalve (other than oysters) densities over less complex reef habitat (Summerson et al. 1995, Grabowski 2002). In addition to offering refuge for both intermediate predators and prey, habitat complexity may increase intermediate predator foraging efficiency through mechanisms that decrease intraand interspecific aggression or competition. Thus, mechanisms driving increased predator foraging efficiency within complex habitats counteract habitat complexity driven benefits to prey survival. In this study, we demonstrate that the effect of habitat complexity on predator foraging efficiency is densitydependent. In particular, habitat complexity increases foraging efficiency at high predator densities by reducing intraspecific interference among mud crabs. Dense aggregations of prey within complex habitats could be analogous to schools of fish, which have been reported to both increase prey survivorship (Turner \&
Pitcher 1986, Krause et al. 1998) and enhance predator foraging efficiency (Sharpe \& Dill 1997, Domenici et al. 2000). Further investigations of how habitat complexity mediates predator-prey dynamics should consider the relative importance of trait- and density-mediated interactions and their resultant impacts across multiple trophic levels.

Acknowledgements. The authors would like to thank A. Baukus, K. Sullivan, D. Gaskill, and K. Gregalis for assistance with the experiment. UNC-IMS provided laboratory space and technical support, for which we are very grateful. This study was supported through funding from the North Carolina Fishery Resource Grant Program (J.H.G.), the University of North Carolina at Chapel Hill graduate fellowship program (J.H.G.) and the National Science Foundation (S.P.P.).

\section{LITERATURE CITED}

Appleberg M, Söderbäck B, Odelström B (1993) Predator detection and perception of predation risk in the crayfish Astacus astacus L. Nordic J Freshw Res 68:55-62

Beck MW (1997) A test of the generality of the effects of shelter bottlenecks in four stone crab populations. Ecology 78: 2487-2503

Beukers JS, Jones GP (1997) Habitat complexity modifies the impact of piscivores on a coral reef fish population. Oecologia 114:50-59

Clark ME, Wolcott TG, Wolcott DL, Hines AH (1999) Intraspecific interference among foraging blue crabs Callinectes sapidus: interactive effects of predator density and prey patch distribution. Mar Ecol Prog Ser 178:69-78

Commito JA, Rusignuolo BR (2000) Structural complexity in mussel beds: the fractal geometry of surface topography. J Exp Mar Biol Ecol 255:133-152

Corona A, Soto LA, Sanchez AJ (2000) Epibenthic amphipod abundance and predation efficiency of the pink shrimp Farfantepenaeus duorarum (Burkenroad, 1939) in habitats with different physical complexity in a tropical estuarine system. J Exp Mar Biol Ecol 253:33-48

Crowder LB, Cooper WE (1982) Habitat structural complexity and the interaction between bluegills and their prey. Ecology 63:1802-1813

Diehl S (1988) Foraging efficiency of three freshwater fish: effects of structural complexity and light. Oikos 53: 207-214

Diehl S (1992) Fish predation and benthic community structure: the role of omnivory and habitat complexity. Ecology 73:1646-1661

Domenici P, Batty RS, Simila T, Ogam E (2000) Killer whales (Orcinus orca) feeding on schooling herring (Clupea harengus) using underwater tail-slaps: kinematic analyses of field observations. J Exp Biol 203:283-294

Fonseca MS, Meyer DL, Hall MO (1996) Development of planted seagrass beds in Tampa Bay, Florida, USA. II. Faunal components. Mar Ecol Prog Ser 132:141-156

Grabowski JH (2002) The influence of trophic interactions, habitat complexity, and landscape setting on community dynamics and restoration of oyster reefs. PhD thesis, University of North Carolina, Chapel Hill, NC

Grabowski JH (2004) Habitat complexity disrupts predatorprey interactions but not the trophic cascade on oyster reefs. Ecology 84:995-1004

Gutierrez JL, Jones CG, Strayer DL, Iribarne OO (2003) Mol- 
lusks as ecosystem engineers: the role of shell production in aquatic habitats. Oikos 101:79-90

Heck KL Jr, Thoman TA (1981) Experiments on predator-prey interactions in vegetated aquatic habitats. J Exp Mar Biol Ecol 53:125-134

Heithaus MR, Dill LM (2002) Food availability and tiger shark predation risk influence bottlenose dolphin habitat use. Ecology 83:480-491

Kelaher BP (2003) Changes in habitat complexity negatively affect diverse gastropod assemblages in coralline algal turf. Oecologia 135:431-441

Krause J, Ruxton GD, Rubenstein D (1998) Is there always an influence of shoal size on predator hunting success? J Fish Biol 52:494-501

Lenihan HS, Peterson CH (1998) How habitat degradation through fishery disturbance enhances impacts of hypoxia on oyster reefs. Ecol Appl 8:128-140

Lenihan HS, Peterson CH, Byers JE, Grabowski JH, Thayer GW, Colby DR (2001) Cascading of habitat degradation: oyster reefs invaded by refugee fishes escaping stress. Ecol Appl 11:764-782

Martin TH, Wright RA, Crowder LB (1989) Non-additive impact of blue crabs and spot on their prey assemblages. Ecology 70:1935-1942

Meyer DL, Townsend EC, Murphy PL (1996) Final report for the project the evaluation of restored wetlands and enhancement methods for existing restorations. NOAA, Silver Springs, MD

Reise K (2002) Sediment mediated species interactions in coastal waters. J Sea Res 48:127-141

Schmitz OJ, Vlastimil K, Ovadia O (2004) Trophic cascades: the primacy of trait-mediated indirect interactions. Ecol Lett 7:153-163

Schriver P, Bøgestrand J, Jeppesen E, Søndergaard M (1995) Impact of submerged macrophytes on fish-zooplanktonphytoplankton interactions: large-scale enclosure experiments in a shallow eutrophic lake. Freshw Biol 33: $255-270$

Editorial responsibility: Otto Kinne (Editor), Oldendorf/Luhe, Germany
Sharpe FA, Dill LM (1997) The behavior of Pacific herring schools in response to artificial humpback whale bubbles. Can J Zool 75:725-730

Sih A (1980) Optimal behavior: can foragers balance two conflicting demands? Science 210:1041-1043

Spanier E, McKenzie TP, Cobb JS, Clancy M (1998) Behavior of juvenile American lobsters, Homarus americanus, under predation risk. Mar Biol 130:397-406

Summerson HC, Peterson CH (1984) Role of predation in organizing benthic communities of a temperate-zone seagrass bed. Mar Ecol Prog Ser 15:63-77

Summerson HC, Peterson CH, Hooper M (1995) Aquacultural production of northern quahogs, Mercenaria mercenaria (Linnaeus, 1758): high water temperatures in the nursery and growth penalties of predator control by gravel. J Shellfish Res 14:25-31

Tegner MJ, Dayton PK (1981) Population structure, recruitment, and mortality of two sea urchins (Strongylocentrotus franciscanus and $S$. purpuratus) in a kelp forest near San Diego, California. Mar Ecol Prog Ser 5:255-268

Turner GF, Pitcher TJ (1986) Attack abatement: a model for group protection by combined avoidance and dilution. Am Nat 128:228-240

Wahle RA (1992) Body-size dependent anti-predator mechanisms of the American lobster. Oikos 65:52-60

Werner EE, Hall DJ (1988) Ontogenetic habitat shifts in bluegill: the foraging rate predation risk trade-off. Ecology 69:1352-1366

Werner EE, Peacor SD (2003) A review of trait-mediated indirect interactions in ecological communities. Ecology 84: $1083-1100$

Werner EE, Gilliam JF, Hall DJ, Mittelbach GG (1983) An experimental test of the effects of predation risk on habitat use in fish. Ecology 64:1540-1548

Winfield IJ (1986) The influence of simulated aquatic macrophytes on the zooplankton consumption rate of juvenile roach, Rutilus rutilus, rudd, Scardinius erythrophthalmus, and perch, Perca fluviatilis. J Fish Biol 29:37-48

Submitted: December 10, 2003; Accepted: May 11, 2004

Proofs received from author(s): July 26, 2004 